\title{
Capitalismo o democracia, ¿UNA FALSA DISYUNTIVA?
}

\author{
Mauricio Andrés Ramíres Gómes \\ Docente do Departamento de \\ Economía da Universidad EAFIT, Medellín, Colômbia.
}

E-mail: maramire@eafit.edu.co

\section{Resumen}

En la lógica del capitalismo actual, la intervención del Estado se constituye en algo dañoso en lo referente a la acumulación. Bajo esta perspectiva, lo que se quiere es un estado de perfil tecnocrático, despolitizado, a servicio del mercado. No obstante, un Estado concebido de esta forma está claramente en la contramano de las exigencias sociales que demandan, por fuerza de la exclusión del proceso económico, un Estado que es representativo del conjunto de las fuerzas sociales. Especular sobre el Estado en esta dirección es lo que se propone en este texto.

Palabras clave: capitalismo; democracia; exclusión social.

a lógica del capitalismo, bajo la visión contemporánea ha propuesto como aspiración normativa el despojar de manera absoluta, a la economía, de la "dañina" intervención del Estado, en sus distintos escenarios: Un Estado que ha actuado directamente como empresario; regulador de la actividad económica, por la vía de la política fiscal, monetaria ó sectorial; prestador de servicios productivos e improductivos en el ámbito de los servicios públicos y de infraestructura; garante de la reproducción de la fuerza de trabajo por medio de la legislación laboral y la seguridad social. En este sentido el sustrato de la preocupación radica entonces en la construcción de Estados despolitizados de corte tecnocrático que garantice las condiciones de reproducción estables de los patrones de acumulación y apropiación individual del capital.

Bajo este contexto se pretende generar mecanismos de flexibilización institucional, que aspiran al reordenamiento de la esfera 
estatal bajo la lógica de generar un dimensionamiento pragmático en términos de la articulación orgánica de la dupla Estado-mercado.

El Estado bajo esta relación dual, adquiere la connotación de ser un ente hegemónico con capacidad de garantizar y ordenar los procesos económicos bajo el carácter legal que lo reviste, y su reconocimiento legítimo en medio de las concepciones democráticas representativas mas ideales.

"Parte de la nueva filosofía política consiste en llevar los principios de la administración de la empresa privada a la gerencia del Estado y a la administración pública en general. Esto implica un cambio radical en la filosofía del Estado que ya no se concibe dentro de los paradigmas teóricos convencionales....la teoría democrática del Estado, por el contrario proyecta una administración pública abierta a los cambios de la opinión y de las fuerzas políticas que compiten dentro del sistema electoral de la democracia política" (Child, 1993)

Ahora bien, si reconocemos la existencia de un funcionamiento autónomo del mercado, el papel que se le podría asignar a la esfera Estatal como expresión formal del poder social, estaría determinado por la asignación del rol fundamental en función de la dinámica económica capitalista en cuanto se convierte en el garante institucional del régimen de propiedad, de las reglas "equitativas" de la pugna competitiva, y estará atento a las fallas del sistema para removerlas, es decir trata de resolver o minimizar las contradicciones del sistema, fortaleciendo de paso los intereses de sectores sociales específicos.

Es claro, bajo este estado de cosas, que si bien el capitalismo se ha despojado de cualquier tipo de vínculos con el Estado, también es cierto que se ha garantizado para si el rodearse de una gama de opciones de derechos, controles y defensas que dan pie a pensar que su preocupación radica no en la prevención de la contradicción social sino en la corrección y ajuste de la contradicción que el mismo sistema por su naturaleza genera.

El sociólogo Francés Alain Touraine, hace un llamado de atención cuando puntualiza la diferencia de asumir la economía como libre de toda interferencia de gestión ineficiente del Estado, a mostrarla como una economía que se autorregula lejos de toda interferencia exógena. Y es bajo esta última consideración, que Touraine describe la esencia del capitalismo hoy: 
“...capitalismo, que no es otra cosa sino esta mundialización de la economía de la cual se habla mucho sin detenerse a caracterizarla. El capitalismo supone una economía de mercado en cuanto que ésta rechaza cualquier control exterior, pues por el contrario, busca actuar sobre la sociedad en bloque en función de sus propios intereses. El capitalismo significa que la sociedad se ve dominada por la economía." (Touraine, 1999)

Esta puntualización nos remite al debate del Estado versus el mercado, el cual creó una falsa disyuntiva en terminos de la exclusión o supremacía y anulación del mercado respecto al Estado. Y resultó ser una falacia discursiva dado que las fronteras nítidas entre los papeles funcionales asignados, tanto para el primero como para el segundo, han sido traspasadas dado el incumplimiento de la promesa de un mundo armónico, pletórico de satisfacciones y de un crecimiento ilimitado.

\section{La democracia}

Los incrementos a nivel mundial de la pobreza, el deterioro creciente del medio ambiente, los conflictos étnicos y religiosos, los aumentos de la criminalidad, la exclusión política, económica y social y en general el deterioro de la calidad de vida, han sido el caldo de cultivo para la eclosión de movimientos sociales que, bajo el amparo de la participación democrática, han colocado entre el deseo y la realidad la viabilidad de la homogeneización económica propuesta desde el capitalismo donde el desarrollo se nos presenta como una consecuencia lógica de la implementación absoluta del llamado "libre mercado".

"La crisis del desarrollo de que hablamos la podemos expresar en estos términos concisos: mientras la economía mundial continua su proceso de expansión y crecimiento global, una visión de conjunto del mundo permite ver que estamos avanzando hacia un colapso de la misma civilización que se está expandiendo y creciendo. Crisis del desarrollo no significa, pues, que lo que hemos entendido como desarrollo esté dejando de verificarse, sino al contrario, que mientras mas avanzamos por el camino de ese desarrollo, más se agudizan los problemas y contradicciones de la sociedad y más nos acercamos al punto en que continuar por dicha senda de desarrollo resultará imposible" (Razeto, 2000). 
Ahora bien, si se coloca la discusión no en el ámbito de lo real, leído desde las crisis, sino desde las aspiraciones ideales de construir sociedades democráticas, encontramos autores como Norberto Bobbio, quien aísla el problema de la contradicción entre Estado versus el mercado de la discusión convencional, y lo coloca una extensión a la disyuntiva que se formula en términos de un Estado democrático versus el mercado.

Para Bobbio el asunto de la democracia no es solamente un problema de mayorías absolutas o la existencia de un marco legal que garantiza la existencia de reglas y procedimientos, es importante además tener las garantías reales de ejercicio de la democracia que han de estar consignados en los llamados derechos fundamentales (de libertad, opinión, expresión, asociación, reunión), que solo pueden ser dados en el seno del Estado liberal, aquel que no solo ejerce un poder de sometimiento a la ley sino que esta limitado por el reconocimiento constitucional de los llamados derechos inviolables del individuo.

"De ahí que el Estado liberal no solamente es el supuesto histórico sino también jurídico del estado democrático. El Estado liberal y el Estado democrático son interdependientes en dos formas: 1) en la línea que va del liberalismo a la democracia, en el sentido que son necesarias ciertas libertades para el correcto ejercicio del poder democrático; 2) en línea opuesta, la que va de la democracia al liberalismo, en el sentido de que es indispensable el poder democrático para garantizar la existencia y persistencia de las libertades fundamentales. En otras palabras: es improbable que un Estado no liberal pueda asegurar un correcto funcionamiento de la democracia, y por otra parte es poco probable que un Estado no democrático sea capaz de garantizar las libertades fundamentales" (Bobbio, 1984)

Bajo esta lógica se podría inferir un paradigma de sociedad democrática, que se sustenta sobre la correlación directa entre desarrollo económico (como expresión más avanzada del capitalismo) y democracia; dicha connotación va de la mano con la idea que la industrialización que conduce al capitalismo de la misma manera debe de conducir a la democracia, dado que esta última resulta ser funcional para la reconciliación de intereses cada vez mas diversos en sociedades mas complejas.

Algunos argumentos apologistas de estas tesis, en medio de la generalidad han planteado que la evidencia empírica muestra como 
la mayoría de los países altamente industrializados reflejan democracias estables, y los países considerados como pobres muestran niveles de inestabilidad democrática fuertes; discusiones que se han inscrito en el ámbito del triunfalismo occidental, luego de la crisis del paradigma socialista, que ha pretendido asimilar la democracia liberal al capitalismo y que aspira a universalizar el modelo democrático de sociedad occidental.

"La tercera limitación para el surgimiento de la democracia estable tiene que ver con la existencia de una estructura social altamente desigual, y todos los hábitos mentales que de ella se derivan. De acuerdo con Tocqueville, la fuerza y estabilidad de la democracia en Estados Unidos se debía al hecho de que la sociedad estadounidense era completamente igualitaria y democrática, mucho antes de que fueran escritas las declaraciones de Independencia y la constitución: los estadounidenses "nacieron iguales". Es decir las tradiciones culturales dominantes traídas a Norteamérica fueron aquellas de Inglaterra y Holanda liberales, más que, digamos, aquellas de la España y Portugal absolutista del Siglo XVII. Brasil y Perú, por contraste heredaron estructuras de clase altamente estratificadas en las que las diferentes clases eran mutuamente hostiles y autosuficientes" (Fukuyama, 1992).

Pero surge un argumento cuestionador de tales generalidades que nos muestran como los casos mas evidentes de países que se han involucrado en procesos de crecimiento económicos acelerado en los últimos 100 años, no han tocado con regímenes democráticos (casos de China, Chile, España, Alemania, Italia), su característica fundamental ha sido la de estados autoritarios, y algunos de ellos alimentados por el paradigma Capitalista.

En esta línea de análisis, autores como Claus Offe y Philippe Schmitter (1995), afirman que es indiscutible que gran parte de las democracias mas estables en el mundo, tienen una correlación directa con aquellos países donde la producción y acumulación económica es de corte privada y su regulación esta regida bajo leyes del mercado; pero aún así, formulan la salvedad en el sentido que una intervención decidida del gobierno de corte democrático, con un amplio apoyo ciudadano puede tener un efecto altamente positivo si se mira desde la diferencia radical y dilemática de un gobierno que distribuye poder y estatus de forma equitativa y una economía que reparte propiedad e ingreso de manera inequitativa; ambigüedad que 
solo será resuelta bajo una óptica de interpretación estructural, en la dimensión compleja del desarrollo económico.

Alrededor de lo anterior quedaría planteado el debate de la necesidad económica de la democracia, es decir ¿La democracia necesita del capitalismo? ó El capitalismo necesita de la democracia?. Sin pretender dar una respuesta absoluta, se podría puntualizar un marco conceptual de referencia que daría pertinencia a tal interrogante.

La democracia se podría asumir bajo la acepción particular de la "democracia económica", entendida esta como la búsqueda de la “...igualdad económica, por la eliminación de los extremos de pobreza y riqueza y, en consecuencia, por una redistribución que persigue el bienestar generalizado." (Sartori, 1993).

En este orden de ideas sería consecuente pensar que la democracia, bajo estos términos, no le es funcional a la racionalidad propuesta por la economía de mercado; dado que tiende a transferir y socializar el patrimonio privado en aras de la equidad social; genera mecanismos de subsidio y asistencia a sectores económicos y sociales que están en dificultades; gasta mas en inversiones sociales que en inversiones productivas.

Si la anterior incompatibilidad se acepta como válida, entonces se asumiría una absoluta contradicción entre capitalismo y democracia, desde la óptica mas radical; o en un espíritu conciliador, quedaría formulado que el capitalismo requiere de una transformación que garantice la salvaguardia y permanencia de la democracia. O en otros términos, parodiando a Bobbio, sería pertinente decir que, si en la década de 1930 fue el capitalismo el que colocó en crisis a la democracia, en la década de 1990 es la democracia la que coloca en crisis al capitalismo.

La alternativa menos radical para darle salida a esta contradicción sería asumir que no se podría hacer una equiparación lineal entre capitalismo y economía de mercado, es decir, es necesario hacer el reconocimiento a una forma de economía de mercado integradora y holística, donde las formaciones sociales se reconocen en su individualidad, y sus procesos asimétricos desde lo político, lo económico y lo social se resuelven no desde las leyes autorreguladoras del mercado, que hacen prevalecer una formación social sobre la otra, desconociendo la heterogeneidad socieconómica. 
Lo anterior nos remite a pensar que el reconocer la existencia de la democracia dentro del contexto de esta economía de mercado ha de conjugar dos escenario, el de la democracia económica y el de la democracia social, entendida esta última como la máxima expresión de la unidad de la sociedad en medio de lo diverso, que establece la diferenciación para efectos de la inclusión.

\section{El estado}

La idea del "darwinismo" económico, o de la supervivencia del más apto, es una de las tesis que ha hecho carrera en medio del discurso institucional de la competencia que busca cada vez ser más perfecta; pero contrario con esto es necesario considerar la pertinencia de la permanencia del Estado como agente regulador de la economía con un doble compromiso, de un lado de carácter redistributivo de la riqueza y la propiedad por medio de los instrumentos de política económica; y de otro lado, como el garante de los procesos de acumulación bajo las políticas de estabilización y crecimiento económico.

La participación del Estado en la actividad económica ha sido un tema de permanente controversia en cuanto a su papel como agente económico activo o como garante de condiciones equitativas para los diferentes agentes económicos. Entendido de una u otra forma, lo cierto es que el Estado en el nivel de desarrollo de las sociedades modernas actuales se ha convertido en pieza fundamental como canalizador del ingreso bajo el papel de la distribución o la estabilización; o por medio de la generación directa de los mismos bajo la función de asignación.

Ahora bien, desde los desarrollos teóricos de Keynes, el papel del Estado ha sido relevante en cuanto que se le justifica el manejo y control discrecional de un conjunto de objetivos e instrumentos de política económica, por medio de los cuales se pretende tener injerencia en la regulación y formalización de las reglas de juego económico tanto para la producción como para el consumo.

El asignarle este papel funcional al Estado hace pensar que este tiene la capacidad de generar beneficios e imponer pérdidas hacia ciertos grupos sociales, lo que conduce ha plantear la no neutralidad del Esta- 
do bajo su papel distributivo, en cuanto que puede extraer y reorientar recursos, bien sea porque profundiza las tendencias espontáneas del libre juego de la oferta y la demanda o por que corrija las distorsiones o cambie radicalmente las condiciones en el proceso de crecimiento económico. Esta última consideración es quizás la que ha sido el foco de la crítica frente al rol desempeñado por el Estado en la economía y que le ha valido un alto componente ideológico en la discusión.

El marco, si se quiere teórico, que ha dimensionado tal discusión gira alrededor de lo que se ha llamado el Estado del bienestar, en el que se concreta el problema del logro de la situación óptima, como conjunto de posiciones en la economía que se consideran mejor que otras posibles. La identificación de las mismas, dependen de la especificación de criterios lo suficientemente objetivos que permitan estructurar una serie de medidas de política económica, "neutrales", que contribuyan al logro del bienestar económico.

Este Estado del bienestar se muestra como la crítica hacia los procesos económicos deshumanizados, inflexibles, omnipotentes y omnipresentes; es una aspiración al derecho a la equidad y un llamado a romper con estructuras de mercado de corte circular, impersonales, homogeneizantes y universalistas. Es una búsqueda menos dramática de identidad entre la democracia y la libertad económica.

Diversos estudios han mostrado un balance positivo de la aplicación de dicho modelo y sus efectos sobre la dinámica del crecimiento económico, en los períodos de 1950 a 1975, que se resumen en cuatro elementos:

1) generó condiciones de relaciones menos contradictorias entre trabajadores y empresarios, asociado a un cambio tecnológico acelerado y un clima de confianza y certidumbre en el largo plazo;

2) incremento de las rentas disponibles, ampliándose la capacidad de consumo, la dinámica de los mercados y el consecuente crecimiento económico.

3) inversión social en infraestructura de servicios básicos colectivos;

4) Garantizó un proceso de expansión del empleo, fundamentalmente en el sector público. 
"En suma la constitución de un Estado del bienestar ... en los últimos cincuenta años ha articulado a las sociedades, dinamizando la economía $\mathrm{y}$ hecho posible que las personas se sientan individuos con futuro y ciudadanos con derechos en la práctica" (Castells, 1994).

Si se tratara de validar este tipo de participación del Estado en alguna economía, este adquiere mayor importancia en aquellas consideradas como no desarrolladas, las cuales han sido el reflejo de comportamientos asimétricos en cuanto a bajos niveles de ingreso per capita y la constante presencia de desigualdades sociales evidenciado en el acceso a la satisfacción de bienes y servicios y alta concentración de la riqueza y la pobreza.

Parte de este escenario se recrea, en la vinculación que se tiene con los mercados externos, como abastecedores de materias primas de bajo nivel de transformación, lo que hace que estas economías sea altamente sensibles al comportamiento de los ciclos de los precios en las economías internacionales. Gran parte de estos mercados fueron intervenidos por los gobiernos (sobre todo productos de minería o de explotación de recursos naturales), los cuales captaron parte significativa de las actividades exportadoras generándose con esto las condiciones reales de financiación de obras públicas en infraestructura y de asistencia social básica.

Esto adquiere una puntualización mayor bajo el modelo proteccionista de la CEPAL, aplicado en América Latina, en medio de procesos de industrialización y creciente modernización de algunos segmentos de la economía a la par que se iban generando nuevos problemas en términos del acceso a tecnologías y la respuesta que era necesario darle desde las políticas públicas en el Estado; que a su vez adquirieron mayor controversia por la naturaleza misma de los regímenes políticos y las alianzas de clase y sectores de clase que de una u otra forma validaron este tipo de acciones públicas bajo la pretensión de amparar, de forma privilegiada, ciertos sectores de la economía.

En síntesis, se podría relevar el rol asumido por el Estado, bajo esta dinámica, en el que se le considera como gran centro de poder desde el cual se pretende anular las diferencias, contrastando con el acceso que tiene a su control los grupos económicos en connivencia con los políticos los que orientan directamente los procesos de acumulación tanto en la esfera pública como privada dándole un matiz particularista a las aspiraciones del desarrollo económico. 
Y es quizás aquí donde se encuentra la mayor vulnerabilidad, que alimenta la crisis del Estado del bienestar, asociada a la pérdida de credibilidad en su aspiraciones de equidad y participación social.

Es indiscutible que la evidencia histórica muestra tres factores fundamentales que catalizaron la crisis del modelo: Los crecientes desequilibrios internos evidenciado en los déficit fiscales; la espiral inflacionaria que repercutió en la dinámica del comercio internacional y la crisis de legitimidad social impulsada por el proceso de segmentación de la sociedad en el que se confrontaron sectores minoritarios enriquecidos con una creciente clase media empobrecida.

Pero es igualmente cierto que no es valida la pretensión triunfalista, de los liberales de la nueva ola económica, de pretender absolutizar la crisis del Estado del bienestar, proponiendo el desmantelamiento total del mismo, en el que la efectividad de su discurso a obedecido mas que por su atractivo teórico, a la conjugación simultánea de hechos históricos (Crisis del paradigma socialista y crisis del Estado del bienestar) que crearon el escenario oportuno para recuperar "....ideas antiguas, expresadas, en términos mas o menos cínicos, desde los orígenes de la industrialización capitalista...” (Castells, 1994) , y mal llamadas, en la actualidad, neoliberales.

\section{Tercera Vía}

Diferente de la preocupación de generar incentivos en los procesos de industrialización desde el Estado, también surge a la par nuevos problemas planteados por las demandas sociales en cabeza de los grupos sociales y económicos emergentes, fruto de la dinámica económica, haciéndose sentir una presión redistributiva sobre el Estado.

Esta dinámica lo que demarca es un Estado que, en principio, tiene muy claramente delimitada sus funciones como agente regulador, con aspiraciones neutrales en su participación en las orientaciones de la economía; luego pasa a un Estado que asume un rol activo y comprometido con los intereses de dichos sectores emergentes con el fin de incorporarlos a las florecientes actividades industriales. Esto contribuye a diluir los posibles niveles de eficiencia que se deberían lograr desde 
el Estado en cuanto que cada vez asume mayores compromisos entorno al financiamiento de nuevas inversiones, el subvencionamiento de la producción privada y la incorporación constante de nuevos grupos sociales a la actividad económica; así las cosas se hace imposible para el Estado hacer compatible simultáneamente un dinamismo en el crecimiento económico, la redistribución del beneficio hacia los nuevos grupos y sostener la eficiencia en las variadas tareas que se asumen desde la esfera económica.

Entorno a lo anterior se puede puntualizar, retomando los trabajos de Bob Jessop (1999), y Manuel Castells (1994), que la búsqueda fundamental radica en la redefinición y recunfiguración del Estado que requiere ser concebido en forma alternativa a la que tradicionalmente orientó el paradigma keynesiano, lo que involucra la estructuración de nuevos mecanismos de participación económica, social y política, que se adecuen a las condiciones del nuevo contexto histórico.

Bajo este deber ser, se inscriben los proyectos de Tercera Vía, que pretenden compatibilizar simultáneamente el rol intervencionista del Estado, la dinámica individualista de los mercados y la democratización de la sociedad.

Anthony Giddens (1998), considerado como el principal ideólogo de esta nueva corriente, contextualiza en cinco dilemas fundamentales, la pertinencia política, económica y social de su propuesta. Es así como parte de asumir en los fenómenos globalizadores de la economía, la opción de anular cualquier radicalismo teórico para su comprensión; formula como la globalización es un fenómeno multidimensional que ha de ser leído no sólo en lo económico sino también en lo político y que si bien plantea un alejamiento con respecto al Estado-nación, igualmente esta presionando constantemente por la regeneración de identidades locales, contribuyendo a la creación de regiones económicas y culturales.

La discusión sobre el individualismo se dialectiza con respecto al colectivismo y se aisla del tratamiento convencional de las decadencias morales, el "darwinismo" económico o la permisividad. Para la Tercera Vía, la lectura es necesario hacerla en el marco de la transformación valorativa tradicional, donde la sociedades se ubican en una fase de transición moral, en el que el punto de llegada ha de ser 
la convergencia entre las responsabilidades individuales y colectivas.

El tercer dilema lo muestra bajo los contornos de la polarización política de la izquierda y la derecha, que se ha visto vulnerada por los fenómenos de la globalización y la crisis del paradigma socialista; en este sentido Giddens sugiere que hablar del centro político bajo este contexto sería hablar de la tesis socialdemócrata del "medio activo" o "centro radical", donde sigue siendo vigente la búsqueda de la igualdad y la justicia social.

También se reconoce la importancia decisiva que posee actualmente el Estado-nacional, el cual no esta llamado a desaparecer sino a transformarse, colocándose en contradicción abierta con las corrientes liberales de la nueva ola, reivindicando la existencia del gobierno en la esfera pública, la dotación del bienestar colectivo y la regulación de los mercados.

Por último, el escenario ecológico se muestra como la mayor exigencia a la economía capitalista en términos de la relación no excluyente que debe de existir entre crecimiento, desarrollo económico y medio ambiente, lo cual exige una reestructuración de la economía capitalista concebida erróneamente bajo la lógica del crecimiento económico indefinido.

En esencia se hace explícita la aspiración a un modelo de economía mixta, que ha sido denominado como la "nueva socialdemocracia", que no ve en el capitalismo y en el libre mercado un escenario hostil y que a diferencia de la "socialdemocracia antigua", no considera los derechos como exigencias incondicionales hacia el gobierno, soportado en el principio de "ningún derecho sin responsabilidad", en el que son responsables tanto el Estado como los destinatarios del bienestar.

La democracia adquiere en este modelo un papel protagónico, cuando se plantea el precepto de "ninguna autoridad sin democracia", en el que queda consignada como única ruta viable de legitimación y consolidación del poder, y mas aún cuando las tradiciones, las costumbres e identidades particulares parecieran disolverse en medio de la hegemonía universalista de los mercados.

Se propone formar democracias hacia abajo, con un carácter mas participativo que representativo, lo que solo podrá ser logrado por una sociedad civil renovada y aliada con el Estado, para "...actuar asociados, cada uno para ayudar, pero también para controlar la acción del otro" (Giddens, 1998). 
La sociedad civil se convierte en parte básica de la propuesta, bajo un papel activo y participativo, creándose las condiciones de encuentro constante entre esta y el Estado, alrededor del gobierno y el estímulo a las iniciativas locales, el control de la esfera pública, y la cogestión del bienestar. En último término la sociedad civil se pondera como la máxima instancia veedora del proceso de democratización económica, social y política, rompiendo con las estructuras clientelistas, privilegiadas y patrimoniales del poder político y económico.

Es importante enfatizar la connotación que adquiere el concepto de sociedad civil, dado que se distancia de las acepciones convencionales, en el sentido de romper con el esquema dicotómico excluyente sociedadestado, que pretende mostrar el conjunto de las relaciones sociales que se encuentran fuera del control coactivo del Estado.

Esta concepción se aleja de los enfoques "anti-estatal" y "postestatal", donde, en el primero, se hace manifiesto el cambio en los balances del poder y el dominio, materializado en la formación de los llamados contrapoderes que posibilita la formación de grupos con aspiraciones de emancipación política. Y en el segundo se muestra un escenario liberado de la sociedad política, dándose la disolución total del Estado. (Bobbio, 1985)

En esencia, se podría decir que la propuesta de sociedad civil que explicita la Tercera Vía, identifica en el Estado un ente que se puede sobreponer para efectos de regulación, pero que simultáneamente no obstaculiza el desarrollo y la renovación de la misma, bajo el rol de la complementariedad.

El nuevo Estado democrático, lo denomina Giddens, "el Estado sin enemigos", que se materializa en escenarios de legitimidad y gobernabilidad, en el que el Estado crea la capacidad de responder institucionalmente a las demandas de la sociedad civil, en lo que la Tercera Vía ha denominado "capacidad de gestión del riesgo", que no consiste exclusivamente en la provisión de seguridad social y económica, tal como lo privilegiaba el tradicional Estado del bienestar, sino que sería multidimensional incluyendo aspectos tecnológicos, científicos, culturales, éticos y de solidaridad.

Como consideración final, se diría que la sociedad civil adquiere sus dimensiones reales bajo la connotación histórica particular, la misma que le imprime un carácter dinámico a su interpretación, es decir, la sociedad 
civil es tan cambiante como la dinámica misma del protagonismo de sus actores sociales se lo permite. Los empresarios y sus organizaciones gremiales, los movimientos cívicos y populares, sindicales, étnicos, campesinos y culturales; todas las posibles opciones de expresiones orgánicas de la sociedad, tienen cabida dentro de la llamada sociedad civil.

La favorabilidad, en el discurso o en la práctica hacia unos u otros, estará determinada por la mayor capacidad de injerencia que tenga en la crítica, y el cambio en los procesos sociales, esto quiere decir que la resolución de intereses y redefinición de valores adquiere un perfil específico que le asigna el sello particular a la sociedad civil que estará en capacidad de reclamar para si la discrecionalidad en el ejercicio del poder.

\section{Referencias Bibliograficas}

BOBBIO, Norberto. Estado, gobierno y sociedad. Por una teoría general de la política. Colombia: Fondo de Cultura Económica, 1997.

BOBBIO, Norberto. El futuro de la democracia. Colombia: Fondo de Cultura Económica, 1997.

CASTELLS, Manuel. El futuro del estado de bienestar en la sociedad informacional. In: GINER, Salvador (Ed.) et al. Buen gobierno y política social. Barcelona: Editorial Ariel, 1994.

CHILD, Jorge. Fin del Estado. Colombia: Editorial grijalbo, 1993.

ESPING, Gosta. Los tres mundos del estado del bienestar: Valencia: Ediciones Alfons el Magnanim, 1993.

FUKUYAMA, Francis. El fin de la historia. El más frío de todos los monstruos fríos. Revista Foro, Colombia, n.18, p. 5-19, 1992.

GIDDENS, Anthony. La tercera vía: la renovación de la socialdemocracia. Taurus, 1998.

JESSOP, Bob. Crisis del Estado de bienestar: Hacia una nueva teoría del Estado y sus consecuencias sociales. Colombia: Universidad Nacional de Colombia. 1999.

OFFE, Claus. Contradicciones en el Estado del Bienestar: Madrid: Alianza editorial, 1990.

OFFE, Claus; SCHMITTER, Philippe. Las paradojas y los dilemas de la democracia liberal. Revista Internacional de Filosofía Política, n.6, p. 5-29,1995. 
RAZETO, Luis. Desarrollo, transformación y perfeccionamiento de la economía en el tiempo. Bolovia: Universidad Bolivariana de Chile y ECO IBEROAMERICANO, 2000.

SARTORI, Giovanni. ¿Qué es la democracia? Colombia: Altamir, 1993.

TOURAINE, Alain. ¿Cómo salir del liberalismo? Paidós, 1999.

\begin{abstract}
According to the logic of current capitalism, the State intervention constitutes something harmful to accumulation. Under such vision, a State of a technocratic, not politicized profile and in service of the market is aimed at. Nevertheless, a State conceived in such a manner, due to the exclusion of the economical process, is clearly against the social demands for a State that is representative of the set of social forces. The purpose of the present article is to speculate about the State in such direction.
\end{abstract}

Key-Hords: capitalism, democracy, social exclusion

\title{
Resumo
}

Na lógica do capitalismo atual a intervenção do Estado se constitui em algo danoso à acumulação. Sob essa visão quer-se um Estado de perfil tecnocrático, despolitizado, a serviço do mercado. Não obstante, um Estado assim concebido está claramente na contramão de exigências sociais que demandam, por força da exclusão do processo econômico, um Estado que seja representativo do conjunto das forças sociais. Especular sobre o Escado nesta direção é o que propõe o texto.

Palarras-chave: capitalismo; democracia; exclusão social. 